\title{
Microwave-assisted extraction and characterization of pectin from citrus fruit wastes for commercial application
}

\author{
${ }^{1}$ Mahmud, M.M., ${ }^{1}$ Belal, M., ${ }^{2}$ Ahmed, S., ${ }^{1}$ Hoque, M.M. and ${ }^{1, *}$ Zzaman, W. \\ ${ }^{I}$ Department of Food Engineering and Tea Technology, Shahjalal University of Science and Technology, \\ Sylhet-3114, Bangladesh \\ ${ }^{2}$ Department of Agro Product Processing Technology, Jashore University of Science and Technology, \\ Jashore-7408, Bangladesh
}

\begin{abstract}
Article history:
Received: 19 October 2020

Received in revised form: 28

November 2020

Accepted: 5 February 2021

Available Online: 10

September 2021
\end{abstract}

Keywords:

Citrus fruit peels,

Pectin extraction,

Microwave-assisted,

FTIR

DOI:

https://doi.org/10.26656/fr.2017.5(5).592

\begin{abstract}
Pectin is an essential hydrocolloid widely used as a gelling, thickening, and stabilizing agent in the food, pharmaceutical, and cosmetic industry. In the present study, an effort has been made to extract pectin from Pomelo (Citrus maxima), Kinnow mandarin (Citrus reticulata) and Citron (Citrus medica) peels with microwave-assisted extraction (MAE) technique using organic citric acid. Pectin extracted with MAE was characterized in terms of yield, ash content, $\mathrm{pH}$, solubility, equivalent weight, methoxyl content, anhydrouronic acid content, and degree of esterification. The extraction conditions had significant effects on physicochemical properties. The results showed that the highest amount of pectin $(24.19 \pm 0.26 \%)$ was obtained from Citrus maxima. Based on DE value all pectins were categorized as low methoxy pectin (LMF). Extracted pectins were highly pure based on AUA content. Structural characterization of extracted pectin from three fruit peels by Fourier Transform Infrared (FT-IR) spectroscopy revealed that pectin has functional groups within the $1740-800 \mathrm{~cm}^{-1}$ spectral region. However, pectin extracted in this study can be used in the manufacturing of low sugar foods such as diet jams and jellies.
\end{abstract}

\section{Introduction}

The high environmental footprint and the large handling cost, encountered as an aftermath of unutilized by-products of food processing industries are increasingly noticeable. Citrus fruits are the world's most abundant crop-producing over 115 million tons annually of which around $45-60 \%$ weight of fruits including peels and seeds are disposed of as a by-product having a negative impact on the environment (Azad et al., 2014; Putnik et al., 2017). In Bangladesh, numerous citrus fruits are grown around the country especially in hilly areas like Chittagong, Sylhet, Cox's Bazar, Norsingdi, Panchagarh, etc. About 157000 metric tons of citrus fruits were produced in the year 2014-2015 (BBS, 2016). The disposal of these biodegradable wastes causes serious environmental problems. Fruit wastes have gotten a reputation for one of the prime sources of civil wastes, which have been an undeniably extreme natural issue. The cheap and promptly accessible utilization of agro-food industry wastes is profoundly practical and limits ecological effect. It is in this manner basic to find satisfactory removal of these peels or means to change into valuable items (Liu et al., 2006; Silva et al., 2008).
Citrus wastes contain various bioactive compounds and a huge amount of pectin with great economic value.

Pectin is an essential hydrocolloid is a complex polysaccharide found in the higher plant's cell wall and middle lamella. Pectin is the methyl-esterified polygalacturonic acid that consists of 300-1000 galacturonic acid units. It is used as a food additive in the food, pharmaceutical, and cosmetic industry due to gelling, thickening, and stabilizing property (Thakur et al., 1997; Quoc et al., 2015; Guo et al., 2017). About 100 million pounds of pectin are consumed every year and annual demand increasing at a rate of $5-6 \%$. The amount of carboxylic acid contained in total carboxylic acid units is named as the degree of esterification (DE) that influences the physical property of pectin. Commercially pectin is categorized into high methoxyl pectin (HMP, DE $>50 \%$ ) and low methoxyl pectin (LMP, DE < 50\%). HMP gives structure, bite, and bakestability to acidic jams, jellies, and confectionary with high sugar content, LMP thickens and give consistency to product used in milk desserts, sauces, dressing, Icecream, cheeses (Thakur et al., 1997; Affandi et al, 2017). In terms of medicinal value, pectin has an important role 
in reducing the risk of heart disease, blood cholesterol, bowel cancer, diarrhoea, toxins and provides dietary fibre for good digestion (Bagde et al., 2017). The widely recognized raw materials for commercial pectin production are citrus albedo, sugar beet pulp, and apple pomace. Recently, researchers have pointed some new sources for pectin production such as banana, grapefruit rind, cacao pod husk, jackfruit, mango peel, melon rind, pumpkin, carrot pomace papaya and passion fruit (Pasandide et al., 2017). Numerous techniques have been applied for the extraction of pectins such as conventional heating with acid, ultrasonic extraction, subcritical water, enzyme extraction, ultra-high pressure, and microwaveassisted extraction (MAE). The most common method of heating with acidified water is time-consuming and causes loss of energy (Putnik et al., 2017).

However, MAE is a promising alternative compared to traditional heating that has escalated rapidly in recent times. MAE provides numerous advantages such as low cost, less time, less solvent, greater extraction rate, and better product. The basic principles involved in MAE are to apply microwave energy to plant molecules by ionic conduction and dipole rotation. Due to microwave, rapid heat generates causing vibration leading to rupture the cell tissues. In terms of pectin extraction, interaction occurs between pectinesterase and pectic substances by microwave that improves pectin extraction (Kute et al., 2015). Besides, parenchyma cells disintegrate and specific surface area increases facilitating plant cell's water absorption capacity (Kratchanova et al., 2004). Generally, mineral acids are used to extract pectin in the traditional heating process. Such mineral acids are corrosive and harmful to equipment, devices, and not eco -friendly (Hosseini et al., 2016).

Pomelo (Citrus maxima) is one of the most wellknown and available fruit in Bangladesh. In the year 2014-15, more than 63000 metric tons of pomelo was cultivated in 900 acres of land (BBS, 2016). Pomelo fruit is freshly eaten and used in food items such as desserts, salads, fruit cocktails, jam, juice combinations, etc. The white fruit peel contains almost $30 \%$ of the total fruit (Methacanon et al., 2014). Outer peel is much soft, thick and easier to remove. Thick peels are used to prepare sweet candies and marmalade (Hameed et al., 2008). A massive amount of peel can be a prospective source for the production of a value-added product. Kinnow mandarin (Citrus reticulata) is a hybrid of King and Willow leaf mandarin. Nowadays it is widely grown in south-east Asia for its sweet taste and more juice. Kinnow mandarin peels account for up to $25 \%$ of total fruit which is rich in antioxidants. In Bangladesh, around 4000 metric tons of orange including Kinnow have produced annually (BBS, 2016). After consuming pulp, this peel waste can be a good source for pectin production. Citron (Citrus medica) also known as Jara lemon is an ancient species widely distributed in oriental countries like China, Vietnam, Iran, India, etc. Citrus medica has been used as an Asian herbal medicine for the treatment of many chronic diseases (He et al., 2014). In Bangladesh, it is mainly found in the hilly areas of Sylhet. The fruit is much bigger with a smooth lemonyellow peel with a low amount of pulp. The outer peel is rich in pectin and is disposed of as a by-product that can be properly converted to a value-added one (Pasandide $e t$ al., 2017).

Fourier Transform Infrared spectroscopy (FTIR) is a quick, non-ruinous strategy dependent on the estimation of absorption in the mid-infrared frequency range. Every spectrum obtained through FTIR will show the structural composition of the analysed sample since hydrocolloids like pectin have intramolecular and intermolecular bonds that retain in this frequency range (Baum et al., 2017). The objectives of the research were to extract pectin from Pomelo (Citrus maxima), Kinnow mandarin (Citrus reticulata), and Citron (Citrus maxima) with the assistance of microwave, to characterize the extracted pectin and to recommend potentiality for commercial production.

\section{Materials and methods}

\subsection{Raw materials and reagents}

Ripe Pomelos, Kinnow-mandarins, and mature Citrons (Figure 1) were obtained from the local market, Sylhet, Bangladesh. For the isolation and characterization of pectin Citric acid anhydrous (UNICHEM, China), Hydrochloric acid (Merck, Germany), Ethanol (Merck, Germany), Sodium hydroxide (Qualikems Fine Chem Pvt Ltd.), Sodium Chloride (UNI -CHEM, China), Potassium Bromide (Merck, Germany) and Phenol Red (Loba Chemie Pvt Ltd, India) were used. Chemicals and some other analytical grade reagents were used for the study.

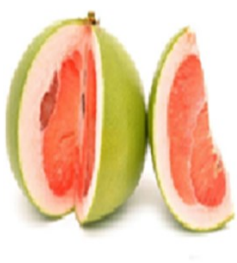

Pomelo
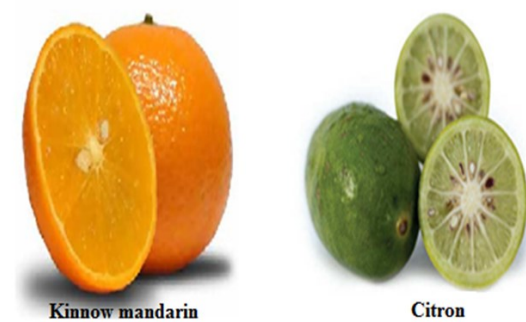

Figure 1. Pictures of pomelo, Kinnow mandarin and citron samples

Pomelo, Kinnow mandarin, and Citrons were physically examined to ascertained their wholesomeness. 
Before cut into pieces, the fruits were washed under tap water to eliminate dirt and soil. For ease of drying, the peels were removed and sliced thinly. They were washed thoroughly with water to remove Glycosides from the bitter taste of the peels. The cut pieces were put on stainless trays and dried in a hot air oven at $50^{\circ} \mathrm{C}$ until their constant weight was found. The dried peels were then grounded by a Blender and passed through a sieve mesh to get a powdered sample. The powdered peels were poured into poly-ethylene bags and stored in a dry place for extraction (Hosseini et al., 2016).

\subsection{Extraction of pectin}

Microwave-assisted extraction of pectin from Pomelo, Kinnow mandarin, and Citrons were performed according to the method described by (Hosseini et al., 2016) with slight modification. The dry powdered peels were poured into an aqueous solution of citric acid adjusted at $\mathrm{pH} 1.5$ at liquid-solid ratio (LSR) of $30(\mathrm{v} / \mathrm{w})$ and thereafter stirred. Extraction was carried out with the help of a domestic microwave oven, at $2450 \mathrm{MHz}$ working frequency, and maximum $850 \mathrm{~W}$ power output. The acid solution containing peels are taken into a steel jar and placed over a rotating disc in the middle of the microwave equipment. Then the solution was extracted with a power of $600 \mathrm{~W}$ and 9 minutes of irradiation time. After the microwave treatment, the mixture was cooled to room temperature. The extract was filtered by pressing through a nylon cloth and then centrifuged at $4000 \mathrm{rpm}$ for 10 mins (Mosayebi et al., 2015). The supernatant was mixed with a double volume of ethanol $(96 \%)(\mathrm{v} / \mathrm{v})$ and kept for $1.5 \mathrm{hrs}$ (Leong et al., 2016). To remove the monosaccharides and disaccharides, the coagulated pectin mass was washed three times with $96 \%$ ethanol. Then the extracted wet pectin was dried in the hot air oven at $40^{\circ} \mathrm{C}$ until a constant weight was obtained. Then the dried pectin is stored in bags for further analysis. The pectin yield (PY) calculation was done according to ( $\mathrm{Li}$ et al., 2012) from the following equation:

$$
\mathrm{PY}=\mathrm{m} / \mathrm{m}_{0} \times 100
$$

Where $\mathrm{m}(\mathrm{g})$ is the weight of dried pectin and $\mathrm{m}_{0}(\mathrm{~g})$ is fruit peel powder weight.

\subsection{Equivalent weight determination}

Equivalent weight determination was done according to (Ranganna, 2007). To calculate the Anhydrouronic acid content and the degree of esterification, an equivalent weight is needed. It is determined by titration with sodium hydroxide at $\mathrm{pH} 7.5$ using a phenol red indicator. In a $250 \mathrm{~mL}$ conical flask, $0.5 \mathrm{~g}$ of extracted pectin (ammonia and ash-free) was taken and diluted with $5 \mathrm{~mL}$ ethanol. Next, $1 \mathrm{~g}$ sodium chloride was poured to sharpen the endpoint. In the solution, $100 \mathrm{~mL}$ deionized water was added with six drops of phenol red indicator. All the extracted pectin was dissolved by stirring. Then, the solution was titrated slowly with $0.1 \mathrm{~N}$ $\mathrm{NaOH}$ until a pink color was appeared due to indicator change. The neutralized solution was kept for methoxyl content determination.

$$
\text { Equivalent weight }(E W)=\frac{\text { Weight of sample } \times 1000}{\mathrm{~mL} \text { of alkali used } \times \text { Normality of alkali }}
$$

\subsection{Determination of methoxyl content $(\mathrm{MeO})$}

Methoxyl content $(\mathrm{MeO})$ was determined by using the (Ranganna, 2007) method. The methoxyl content or level of esterification is a significant factor in controlling the setting time of pectins, the affectability to polyvalent cations, and their handiness in the arrangement of low solid gels, films, and fibers. It is resolute by the saponification of the pectin and titration of the freed carboxyl groups. The methoxyl contents were dictated by pouring $25 \mathrm{~mL}$ of $0.25 \mathrm{~N} \mathrm{NaOH}$ to the neutral solution, thoroughly mixed, and was permitted to stand for 30 minutes at room temperature in a stoppered flask. Then $25 \mathrm{~mL}$ of $0.25 \mathrm{~N} \mathrm{HCl}$ was added and titrated with $0.1 \mathrm{~N}$ $\mathrm{NaOH}$ to a similar endpoint as before. Methoxyl content

$$
\mathrm{MeO}(\%)=\frac{\mathrm{mL} \text { of Alkali } \times \text { Normality of alkali } \times 3.1}{\text { Wt of sample }}
$$

\subsection{Determination of total anhydrouronic acid content (AUA)}

Total Anhydrouronic Acid Content (AUA) of pectin was obtained by the method as described by (Suhaila et al., 1995).

Anhydrouronic Acid Content, AUA (\%) $=\frac{176 \times 0.1 \mathrm{z} \times 100}{\mathrm{w} \times 1000}+\frac{176 \times 0.1 \mathrm{y} \times 100}{\mathrm{w} \times 1000}$

2.6 Determination of degree of esterification (DE)

The Degree of Esterification (DE) of pectin was measured based on methoxyl and AUA content according to (Ranganna, 2007) method.

The Degree of Esterification, DE $(\%)=\frac{176 \times \% \mathrm{MeO}}{31 \times \% \mathrm{AUA}} \times 100$

\subsection{Determination of ash content and $p H$}

Ash content of pectin was determined according to (Ranganna, 2007) and the $\mathrm{pH}$ of extracted pectin was determined by (Aina et al., 2012).

\subsection{Determination of solubility of pectin in hot and cold} water

The determination of the solubility of pectin in water and alkali was done according to the method described by (Bagde et al., 2017). 
2.9 FT-IR measurement methods for pectin's structural characterization

FTIR microspectroscopy is used for the characterization of pectin and to confirm the isolated pectin from cell wall material (CWM).FT-IR spectrum of polysaccharide was obtained at an of $1 \mathrm{~cm}^{-1}$. The sample was mixed with $\mathrm{KBr}$ (spectroscopic grade) and squeezed into a $3 \mathrm{~mm}$ pellet. The 50 scans were entered before Fourier transformation. Spectra were recorded in the transparent mode from 4000 to $400 \mathrm{~cm}^{-1}$ using an IR Prestige21 (Shimadzu corporation, 2018). Around 0.1 to $1.0 \%$ pectin sample was well blended with 200 to 250 $\mathrm{mg}$ fine alkali halide $(\mathrm{KBr})$ powder and then finely pulverized and put into a pellet-shaping die. Under a vacuum of several $\mathrm{mm} \mathrm{Hg}$, a force of approximately 8 tons was applied to form transparent pellets for several minutes. To eliminate air and moisture from the $\mathrm{KBr}$ powder, degassing was done. Broken pellets due to improper vacuum might cause light scattering. The background measurement was done on a pellet holder containing $\mathrm{KBr}$ only without sample used as a correction for infrared light Scattering losses in the pellet and moisture adsorbed on the $\mathrm{KBr}$ (Tatzber et al., 2007).

\subsection{Sensorial property}

An attempt has been made to prepare low sugar Apple jam with pomelo pectin and its organoleptic property was evaluated. A 9-point hedonic scale $(1=$ dislike extremely and $9=$ like extremely) was used for sensory analysis of extracted pectin to determine the consumer acceptability according to (Sandhu et al., 2012). The attributes for the evaluation were appearance, taste, aroma, texture, and overall acceptance. The mean value scores were calculated for each attribute.

\subsection{Statistical analysis}

The experiments were carried out in triplicates and data obtained from experiments were gathered and analysed using the Origin 8.0 version. Analysis of variance was used to determine the significant difference between Citrus maxima, Citrus reticulata, and Citrus medica. A significant difference was determined at $\mathrm{p} \leq$ 0.05 .

\section{Results and discussion}

\subsection{Yield of extracted pectin}

Total pectin precipitated of Citrus maxima, Citrus reticulata, and Citrus medica were calculated in this study. Table 1 shows the total pectin content found with the assistance of microwave radiation and using organic citric acid from Pomelo, Kinnow mandarin, and Citron. Usually, pectin source and extraction conditions predetermine pectin yield (irradiation time, microwave power, pH) (Hosseini et al., 2016). The amounts of extracted pectins were significantly different. In this study, the highest amount of pectin was extracted from Citrus maxima $(24.19 \pm 0.26 \%)$, and the lowest amount of pectin obtained from Citrus medica (12.44 $\pm 0.27 \%)$. Pectin obtained from Citrus maxima was close to the amount (23.83\%) obtained by Quoc et al. (2015) from pomelo peels by microwave treatment but higher than the amount as reported by Roy et al. (2018) for pomelo $(16.073 \pm 0.651 \%$ and $16.740 \pm 0.488 \%)$. Pectin extracted from Kinnow mandarin (Citrus reticulata) by MAE was $16.13 \pm 0.20 \%$. The value was comparable with jackfruit rind pectin $(14.81 \pm 1.02 \%)$ as reported by Leong et al. (2016). Although it was lower than the amount (19.24\%) according to Prakash et al. (2013), it was greater than traditional heat extraction from orange peel $(6 \%)$ as reported by Bagde et al. (2017) and from sweet orange (1.68\%) by Aina et al. (2012). The lowest amount of pectin extracted in the present study was from Citrus medica $(12.44 \pm 0.27 \%)$. The amount was supported by Kute et al. (2015) for orange peel pectin (13.32\%). Besides that, the value was greater than orange peel pectin (6\%) as reported by Bagde et al. (2017) and from sweet orange $(1.68 \%)$ by Aina et al. (2012). MAE has been proved to enhance pectin yield to a great extent. Polar water generates rapid heat energy due to microwave radiation. As a result, cell rupture occurred that increases extraction yield (Kute et al., 2015). Besides, eco-friendly organic acids showed better results

Table 1. Physico-chemical characteristics of extracted pectin

\begin{tabular}{|c|c|c|c|}
\hline Characteristics & Citrus maxima & Citrus reticulata & Citrus medica \\
\hline Pectin Yield (\%) & $24.19 \pm 0.26^{\mathrm{c}}$ & $16.13 \pm 0.20^{\mathrm{b}}$ & $12.44 \pm 0.27^{\mathrm{a}}$ \\
\hline Equivalent Weight, g/mol & $387.43 \pm 12.03^{\mathrm{c}}$ & $248.21 \pm 3.44^{\mathrm{a}}$ & $319.79 \pm 5.82^{b}$ \\
\hline Methoxyl Content, \% & $6.09 \pm 0.04^{\mathrm{c}}$ & $4.91 \pm 0.10^{\mathrm{b}}$ & $4.26 \pm 0.10^{\mathrm{a}}$ \\
\hline Anhydrouronic Acid, \% & $70.51 \pm 1.07^{\mathrm{a}}$ & $88.93 \pm 1.42^{\mathrm{b}}$ & $72.98 \pm 1.42^{\mathrm{a}}$ \\
\hline Degree of Esterification, \% & $49.17 \pm 1.06^{\mathrm{c}}$ & $31.36 \pm 0.17^{\mathrm{a}}$ & $33.14 \pm 0.26^{\mathrm{b}}$ \\
\hline Ash Content, $\%$ & $1.1 \pm 0.1^{\mathrm{b}}$ & $1.45 \pm 0.02^{\mathrm{c}}$ & $0.95 \pm 0.02^{\mathrm{a}}$ \\
\hline $\mathrm{pH}$ & $3.0 \pm 0.02^{\mathrm{a}}$ & $3.06 \pm 0.02^{\mathrm{a}}$ & $2.93 \pm 0.03^{\mathrm{a}}$ \\
\hline
\end{tabular}

Values are expressed as mean \pm standard deviation of triplicate testing. Values with different superscripts within the same row are significantly different $(\mathrm{p} \leq 0.05)$. 
enhancing pectin extraction than mineral acids (Seixas et al., 2014).

\subsection{Equivalent weight (EW)}

The equivalent weight of extracted pectin from Citrus maxima, Citrus reticulata, and Citrus medica was significantly different ranged within $387.43 \pm 12.03$, $248.21 \pm 3.44$, and $319.79 \pm 5.82$, respectively (Table 1), which resembled pectin extracted from orange peel which ranged 318.50 to 378.80 (Hend et al., 2015). However, the equivalent weight of the present study was lower than for pomelo pectin ranged from $540.04 \pm 11.89$ to $711.33 \pm 13.77$ (Roy et al., 2018), but higher than lemon (100) and orange (86.87) pectin as reported by Bagde et al. (2017). The degree of maturity significantly affected EW, Overripe fruits showed lower equivalent weight (368 \pm 3$)$ than mature fruits $(1632 \pm 137)$ (Azad et al., 2014). Increased microwave power and longer irradiation time significantly decreased $\mathrm{EW}$ for watermelon rind pectin. Besides, citric acid might affect decreasing EW. Higher partial degradation caused the lower equivalent weight of extracted pectin and the amount of free acid might also influence equivalent weight content (RamLi and Nazaruddin, 2011).

\subsection{Methoxyl content (MeO)}

Methoxyl content $(\mathrm{MeO})$ is a significant factor that controls pectin's setting time, the gel-forming ability of pectin and bonding with metallic ions largely depend on it (Devi et al., 2014). Table 1 shows that there was a significant difference in methoxyl content among the three species. Citrus maxima had higher methoxyl content represented as $6.09 \pm 0.04 \%$ and Citrus medica had the lowest methoxyl content represented as $4.26 \pm 0.10 \%$. Citrus reticulata had a methoxyl content of $4.91 \pm 0.10 \%$. These values were a resemblance to orange peel pectin (5.58-5.89\%) as reported by (Devi et al., 2014). Literature showed that the mature (4.24\%) and overripe $(4.26 \%)$ lemon pomace pectin had less methoxyl content $(10.25 \%)$ than a premature one, the ripening caused the methoxyl content to decrease while the sugar content, spreading quality and sugar-binding capacity of pectin increased (Azad et al., 2014). Besides that, the source and mode of extraction influenced the methoxyl content of pectin that varies from $0.2-12 \%$ (Bagde et al., 2017). Based on methoxyl content value, the pectin extracted in this study was categorized as low methoxyl pectin.

\subsection{Anhydrouronic acid content (AUA)}

The purity of extracted pectin depends on total anhydrouronic acid content whose value should not be less than 65\% (Shaha et al., 2013). In the present study, the highest amount of AUA obtained from Citrus reticulata was $88.93 \pm 1.42 \%$ and the lowest amount of AUA obtained from Citrus maxima was $70.51 \pm 1.07 \%$. All the values from this study were greater than $65 \%$ can be categorized as pure pectin. These values are supported by Roy et al. (2018) for pomelo pectin ranged $84.29 \pm 5.83 \%$ for $\mathrm{pH} 1.5$ and $85.57 \pm 4.96 \%$ for $\mathrm{pH} 2.0$. These values were higher than dragon fruit pectin ranged $45.25 \%$ to $54.44 \%$, low anhydrouronic acid means retention of high protein, starch, and sugars on extracted pectin (Ismail et al., 2012). The use of citric acid significantly increased AUA recovery for orange peel pectin (Devi et al., 2014) and Kaffir lime pectin (Shaha et al., 2013). The purification method used in this study is the alcohol precipitation procedure (APP). According to Yapo (2009), the metal-ion precipitation method (MPP) is more effective than APP and dialysis method. MPP is more effective than APP in removing ash, proteins. Although an effective method, MPP adversely affects pectin yield and generates huge effluents causing hazards to the environment (Shaha et al., 2013).

\subsection{Degree of esterification (DE)}

In this study, the degree of esterification (DE) for the isolated pectin from Citrus maxima, Citrus reticulata and Citrus medica were found $49.17 \pm 1.06 \%, 31.36 \pm 0.17 \%$, and $33.14 \pm 0.26 \%$ respectively and they were significantly different (Table 2). These values were close to the DE value for Orange peel pectin which is $35.85 \%$ by citric acid and $48.13 \%$ by nitric acid (Devi et al., 2014). DE values of the present study were lower than the pomelo pectin which was $61.19 \pm 2.83 \%$ for $\mathrm{pH} 1.5$ and $70.79 \pm 1.77 \%$ for $\mathrm{pH} 2.0$ as reported by (Roy et al., 2018) and higher than the Citrus macroptera

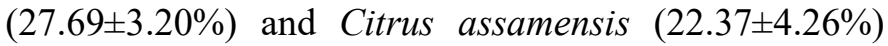
pectin. Overripe lemon pomace pectin showed a lower DE value $(33.59 \pm 0.17 \%)$ than premature $(79.51 \pm 0.36 \%)$ and mature $(70.39 \pm 4.20 \%$ ) ones (Azad et al., 2014). DE value varied depending on species, tissue, and maturity and it decreases with maturity. Pectin converted to protopectin with increasing sugar and soft texture results in low DE (Devi et al., 2014). Low DE value might be due to high microwave radiation, low $\mathrm{pH}$, and longer irradiation time. Hosseini reported that DE of sour orange peel pectin decreases with large microwave power, irradiation time, and low $\mathrm{pH}$ because this harsh condition accelerates the de-esterification of polygalacturonic chains (Hosseini et al., 2016). Besides citric acid significantly lowered DE value for orange pectin (Devi et al., 2014). Based on DE value pectin extracted was classified as low methoxy pectin (LMP), $\mathrm{DE}<50$. The mechanism for gel formation depends on the pectin type. With low sugar or even without sugar, LMP can form gels in divalent cations. LMP produced gels independent of sugar content and they also are so 
Table 2. The solubility of pectin in alkali and water

\begin{tabular}{cccc}
\hline Characteristics & Citrus maxima & Citrus reticulata & Citrus medica \\
\hline Solubility in Cold Water & Insoluble & Insoluble & Insoluble \\
Solubility in Hot Water & Mixture dissolved & Slightly dissolved & Mixture dissolved \\
Solubility in Cold Alkali & Yellow precipitated & Yellow precipitated & Yellow precipitated \\
Solubility in Hot Alkali & Dissolved and turned yellowish & Dissolved and turned brownish & Dissolved and turned yellowish \\
\hline
\end{tabular}

sensitive to $\mathrm{pH}$ like HM-pectins (Shaha et al., 2013). LMP can be used as a gelling, thickening, and stabilizing agent in low sugar jams and recipes as high sugar is not necessary for gel formation. Furthermore, it will form a thermo-irreversible gel when heating at a high temperature that would normally melt it (Tiwari et al., 2017).

\section{$3.6 \mathrm{pH}$ and ash content and solubility}

The $\mathrm{pH}$ of pectin extracted in this study from Citrus maxima, Citrus reticulata, and Citrus medica were 3.0, 3.06 , and 3.93 respectively (Table 1). These values were lower than the lemon (4.1), orange (3.6), and grape (4.0) fruit pectin reported by Aina et al. (2012) and higher than orange pectin by sundried (2.58) as reported by Hend et al. (2015). However, the pectin obtained in this study is acidic. There was no significant difference among those. The ash content of the extracted pectin from pomelo, know mandarin and citron were $1.1 \%$, $1.45 \%$, and $0.95 \%$ respectively (Table 1 ). These were lower than the lemon pomace pectin ranged from $2.41 \pm 0.51 \%$ to $4.06 \pm 0.29 \%$ as reported by Azad et al. (2014). For good gel formation, ash content should be within $10 \%$. Therefore, the ash content found in this experiment indicated the purity of the pectin. The solubility of extracted pectin in alkali and water showed in Table 2.

\subsection{FT-IR spectroscopy}

FTIR microscopy was employed to confirm the isolated pectin from the cell wall material of Pomelo, Kinnow mandarin, and Citron. Figure 2 represents the spectra of studied pectin of Pomelo, Kinnow mandarin, and Citron respectively. Several absorption peaks between 3200 and $3600 \mathrm{~cm}^{-1}$ were owing to $\mathrm{OH}$ stretching. The peak in the range 2850 to $3000 \mathrm{~cm}^{-1}$ was related to $\mathrm{CH}$ stretching vibrational modes including $\mathrm{CH}$, $\mathrm{CH}_{2}$, and $\mathrm{CH}_{3}$ groups (Pasandide et al., 2017). Also, the peak at $1753.37 \mathrm{~cm}^{-1}$ for Citrus maxima, $1740.83 \mathrm{~cm}^{-1}$ for Citrus reticulata, and $1753.37 \mathrm{~cm}^{-1}$ for Citrus medica was corresponding to stretching vibration of methylesterified carboxyl $(\mathrm{C}=\mathrm{O})$ groups. Besides, peak at $1643.42 \mathrm{~cm}^{-1}$ and $1412.92 \mathrm{~cm}^{-1}$ for Citrus maxima, 1640.53 , and $1398.45 \mathrm{~cm}^{-1}$ for Citrus reticulata, 1632.81 $\mathrm{cm}^{-1}$, and $1402.31 \mathrm{~cm}^{-1}$ for Citrus medica denote antisymmetric and symmetric stretching of the carboxylate groups respectively (Hosseini et al., 2016). The regions between 800 and $1300 \mathrm{~cm}^{-1}$ are termed as 'fingerprint' regions for each polysaccharide since the position and intensity of the individual band in the regions are unique for each polysaccharide. These might be due to $\mathrm{C}-\mathrm{O}$ stretching, (O-C-O) asymmetric stretching, (C-O) stretching, and (C-C) stretching of pectic glycosidic link and ring vibration which are difficult to interpret. Thus, it is confirmed that pectin was successfully extracted from Citrus maxima, Citrus reticulata, and Citrus medica using the MAE method.
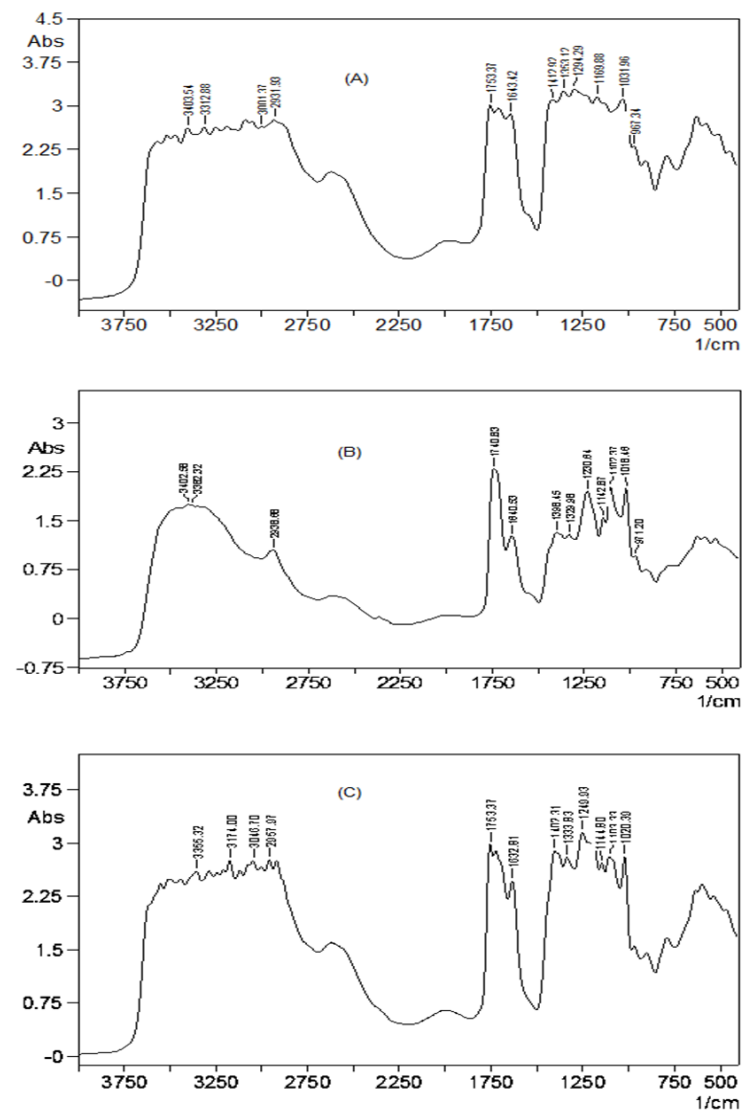

Figure 2. FTIR spectra of Pomelo (A), Kinnow mandarin (B) and Citron (C) peel pectin

\subsection{Sensorial property}

Evaluating all sensory aspects, the results presented in Table 3 were desirable. All of the attributes are a resemblance to Pitomba pulp jam. The taste was the most appreciated attribute, which had an average score of 8.05 interpreted as liked very much. However, since the fruit did not have a strong aroma, the aroma attributes were less appreciated by the evaluators (score of 6.9 \pm 1.21 ). The appearance of the jam was also moderately liked by the evaluators. Colour and aroma depend on reducing sugar and amino acids which is responsible for the Maillard reaction that gives desirable brown colour and 
aroma of foods (Zhang et al., 2008). Although the amount of sugar used was very low $(10 \%)$, the texture was evaluated well with a score of $7.7 \pm 1.13$. Low methoxy pectin gelation occurs in the presence of $\mathrm{Ca}^{2+}$ ions, both with and without sugar (Broomes et al., 2010). The overall acceptability by the evaluators was interpreted as moderately liked (score $7.45 \pm 1.0$ ). Thus, the extracted low methoxy pomelo pectin can be applied to make low sugar products.

Table 3. Sensorial property of low sugar apple jam incorporated pomelo pectin

\begin{tabular}{cc}
\hline Attributes & Low sugar apple jam \\
\hline Appearance & $7.25 \pm 1.25$ \\
Taste & $8.05 \pm 1.09$ \\
Aroma & $6.9 \pm 1.21$ \\
Texture & $7.7 \pm 1.13$ \\
Overall Acceptance & $7.45 \pm 1.0$ \\
\hline
\end{tabular}

Values are expressed as mean \pm standard deviation.

\section{Conclusion}

Pectin is an important hydrocolloid widely used in the food, pharmaceutical, and cosmetic industry. In the present study, a cost-effective and efficient method of microwave-assisted extraction (MAE) has been successfully applied using organic citric acid to extract pectin from Pomelo, Kinnow mandarin, and Citron peels. The yield and pectin properties significantly depended on extraction conditions. The highest yield was obtained from pomelo peels with a higher DE value. All the extracted pectin was categorized as low methoxy pectin (LMP) based on DE value and classified as highly pure pectin based on anhydrouronic acid content. However, no significant difference was observed in the pectin physical structure. Moreover, using Fourier Transform Infrared (FTIR) spectroscopy structural characterization was confirmed as well. Sensory evaluation of low sugar apple jam with pomelo pectin was also satisfactory. Thus, pectin can be commercially extracted from Pomelo, Kinnow mandarin and Citron peels using the MAE technique contributes to greater economic interest. Further study towards optimization of pectin from individual species and mechanisms behind different techniques should be investigated.

\section{Acknowledgments}

Authors thanks the University Grants Commission of Bangladesh for their funding to carry out the research.

\section{References}

Affandi, N., Zzaman, W., Yang, T.A. and Easa, A.M. (2017). Production of Nigella sativa Beverage
Powder under Foam Mat Drying Using Egg Albumen as a Foaming Agent. Beverages, 3(1), 9. https://doi.org/10.3390/beverages3010009

Aina, V.O., Barau, M., Mamman, O.A., Zakari, A., Haruna, H. and Baba Abba, Y. (2012). Extraction and Characterization of Pectin from Peels of Lemon (Citrus limon), Grape Fruit (Citrus paradisi) and Sweet Orange (Citrus sinensis). British Journal of Pharmacology and Toxicology, 3(6), 259-262.

Azad, A., Ali, M., Akter, M. S., Rahman, M.J. and Ahmed, M. (2014). Isolation and characterization of pectin extracted from lemon pomace during ripening. Journal of Food and Nutrition Sciences, 2(2), 30-35. https://doi.org/10.11648/j.jfns.20140202.12

Bagde, P.P., Dhenge, S. and Bhivgade, S. (2017). Extraction of pectin from orange peel and lemon peel. International Journal of Engineering Technology Science and Research, 4(3), 1-7.

Baum, A., Dominiak, M., Vidal-Melgosa, S., Willats, W.G.T., Søndergaard, K.M., Hansen, P.W. and Mikkelsen, J.D. (2017). Prediction of Pectin Yield and Quality by FTIR and Carbohydrate Microarray Analysis. Food and Bioprocess Technology, 10(1), 143-154. https://doi.org/10.1007/s11947-016-1802-2

BBS, (2016). Yearbook of Agricultural Statistics-2015 (27th Series). Retrieved from Bangladesh Bureau of Statistics (BBS) website: http://bbs.portal.gov.bd/ sites/default/files/files/bbs.portal.gov.bd/ page/1b1eb817_9325_4354_a756_3d18412203e2/ Yearbook-2015.pdf

Broomes, J. and Badrie, N. (2010). Effects of lowmethoxyl pectin on physicochemical and sensory properties of reduced-calorie sorrel/roselle (Hibiscus sabdariffa L.) jams. The Open Food Science Journal, 4, 48-55. https:// doi.org/10.2174/1874256401004010048

Devi, W.E., Shukla, R., Abraham, A., Jarpula, S. and Kaushik, U. (2014). Optimized Extraction Condition and Characterization of Pectin from Orange Peel. International Journal of Research in Engineering and Advanced Technology, 2(2), 1-9.

Guo, X., Zhao, W., Liao, X., Hu, X., Wu, J. and Wang, $X$. (2017). Extraction of pectin from the peels of pomelo by high-speed shearing homogenization and its characteristics. LWT - Food Science and Technology, 79, 640-646. https://doi.org/10.1016/ j.lwt.2016.12.001

Hameed, B., Mahmoud, D. and Ahmad, A. (2008). Sorption of basic dye from aqueous solution by pomelo (Citrus grandis) peel in a batch system. Colloids and Surfaces A: Physicochemical and 
Engineering Aspects, 316(1-3), 78-84. https:// doi.org/10.1016/j.colsurfa.2007.08.033

He, Z., Liang, F., Zhang, Y. and Pan, Y. (2014). Watersoluble polysaccharides from finger citron fruits (Citrus medica L. var. sarcodactylis). Carbohydrate Research, 388, 100-104. https://doi.org/10.1016/ j.carres.2013.12.020

Hend, G., Pawar, P., Dhingra, A. and Adule, P. (2015). Isolation and Characterization of Orange Peel Pectin Extracted by Various Drying Methods. International Journal of Researches in Biosciences, Agriculture and Technology, 6, 5-7.

Hosseini, S.S., Khodaiyan, F. and Yarmand, M.S. (2016). Optimization of microwave assisted extraction of pectin from sour orange peel and its physicochemical properties. Carbohydrate Polymers, 140, 59-65. https://doi.org/10.1016/ j.carbpol.2015.12.051

Ismail, N.S.M., RamLi, N., Hani, N.M. and Meon, Z. (2012). Extraction and characterization of pectin from dragon fruit (Hylocereus polyrhizus) using various extraction conditions. Sains Malaysia, 41(1), 41-45.

Kratchanova, M., Pavlova, E. and Panchev, I. (2004). The effect of microwave heating of fresh orange peels on the fruit tissue and quality of extracted pectin. Carbohydrate polymers, 56(2), 181-185. https://doi.org/10.1016/j.carbpol.2004.01.009

Kute, A., Mohapatra, D., Babu, B. and Sawant, B. (2015). Optimization of microwave assisted extraction of pectin from orange peel using response surface methodology. Journal of Food Science and Technology, 3(2), 62-70.

Leong, C., Noranizan, M., Kharidah, M. and Choo, W. (2016). Physicochemical properties of pectin extracted from jackfruit and chempedak fruit rinds using various acids. International Food Research Journal, 23(3), 973-978.

Li, D.-Q., Jia, X., Wei, Z. and Liu, Z.-Y. (2012). BoxBehnken experimental design for investigation of microwave-assisted extracted sugar beet pulp pectin. Carbohydrate Polymers, 88(1), 342-346. https:// doi.org/10.1016/j.carbpol.2011.12.017

Liu, Y., Shi, J. and Langrish, T. (2006). Water-based extraction of pectin from flavedo and albedo of orange peels. Chemical Engineering Journal, 120(3), 203-209. https://doi.org/10.1016/j.cej.2006.02.015

Methacanon, P., Krongsin, J. and Gamonpilas, C. (2014). Pomelo (Citrus maxima) pectin: Effects of extraction parameters and its properties. Food Hydrocolloids, 35, 383-391. https://doi.org/10.1016/ j.foodhyd.2013.06.018
Mosayebi, V. and Tabatabaei Yazdi, F. (2015). Optimization of microwave assisted extraction (MAE) of pectin from black mulberry (Morus nigra L.) pomace. Journal of Food and Bioprocess Engineering, 1(2), 34-48.

Pasandide, B., Khodaiyan, F., Mousavi, Z.E. and Hosseini, S.S. (2017). Optimization of aqueous pectin extraction from Citrus medica peel. Carbohydrate Polymers, 178, 27-33. https:// doi.org/10.1016/j.carbpol.2017.08.098

Prakash, M.J., Sivakumar, V., Thirugnanasambandham, K. and Sridhar, R. (2013). Optimization of microwave assisted extraction of pectin from orange peel. Carbohydrate Polymers, 97(2), 703-709. https://doi.org/10.1016/j.carbpol.2013.05.052

Putnik, P., Bursać Kovačević, D., Režek Jambrak, A., Barba, F.J., Cravotto, G., Binello, A. and Shpigelman, A. (2017). Innovative "green" and novel strategies for the extraction of bioactive added value compounds from citrus wastes - a review. Molecules, 22(5), 680. https://doi.org/10.3390/ molecules 22050680

Quoc, L., Huyen, V., Hue, L., Hue, N., Thuan, N., Tam, N. and Duy, T. (2015). Extraction of pectin from pomelo (Citrus maxima) peels with the assistance of microwave and tartaric acid. International Food Research Journal, 22(4), 1637-1641.

RamLi and Nazaruddin. (2011). Effect of ammonium oxalate and acetic acid at several extraction time and $\mathrm{pH}$ on some physicochemical properties of pectin from cocoa husks (Theobroma cacao). African Journal of Food Science, 5(15), 790-798. https:// doi.org/10.5897/AJFS11.107

Ranganna, S. (2007). Handbook of Analysis and Quality Control for Fruit and Vegetable Products, 2nd ed. New Delhi: Tata McGraw Hill Publishing Co., Ltd.

Roy, M.C., Alam, M., Saeid, A., Das, B.C., Mia, M., Rahman, M. and Ahmed, M. (2018). Extraction and characterization of pectin from pomelo peel and its impact on nutritional properties of carrot jam during storage. Journal of Food Processing and Preservation, 42(1), 1-9. https://doi.org/10.1111/ jfpp.13411

Sandhu, S.K., Oberoi, H.S., Dhaliwal, S.S., Babbar, N., Kaur, U., Nanda, D. and Kumar, D. (2012). Ethanol production from Kinnow mandarin (Citrus reticulata) peels via simultaneous saccharification and fermentation using crude enzyme produced by Aspergillus oryzae and the thermotolerant Pichia kudriavzevii strain. Annals of Microbiology, 62(2), 655-666. https://doi.org/10.1007/s13213-011-0302-x 
Seixas, F.L., Fukuda, D.L., Turbiani, F.R.B., Garcia, P.S., Petkowicz, C.L.D.O., Jagadevan, S. and Gimenes, M.L. (2014). Extraction of pectin from passion fruit peel (Passiflora edulis f. flavicarpa) by microwave-induced heating. Food Hydrocolloids, 38, 186-192. https://doi.org/10.1016/ j.foodhyd.2013.12.001

Shaha, R.K., Punichelvana, Y.N.A. and Afandi, A. (2013). Optimized extraction condition and characterization of pectin from kaffir lime (Citrus hystrix). Research Journal of Agriculture and Forestry Sciences, 1(2), 1-11.

Silva, I.M., Gonzaga, L.V., Amante, E.R., Teófilo, R.F., Ferreira, M.M. and Amboni, R.D. (2008). Optimization of extraction of high-ester pectin from passion fruit peel (Passiflora edulis flavicarpa) with citric acid by using response surface methodology. Bioresource Technology, 99(13), 5561-5566. https:// doi.org/10.1016/j.biortech.2007.10.058

Suhaila, M. and Zahariah, H. (1995). Extraction and characterisation of pectin from various tropical agrowastes. ASEAN Food Journal, 10(2), 43-50.

Tatzber, M., Stemmer, M., Spiegel, H., Katzlberger, C., Haberhauer, G. and Gerzabek, M.H. (2007). An alternative method to measure carbonate in soils by FT-IR spectroscopy. Environmental Chemistry Letters, 5(1), 9-12. https://doi.org/10.1007/s10311006-0079-5

Thakur, B.R., Singh, R.K. and Handa, A.K. (1997). Chemistry and uses of pectin--a review. Critical Review Food Science and Nutrition, 37(1), 47-73. https://doi.org/10.1080/10408399709527767

Tiwari, A.K., Saha, S.N., Yadav, V.P., Upadhyay, U.K., Katiyar, D. and Mishra, T. (2017). Extraction and Characterization of Pectin from Orange Peels. International Journal of Biotechnology and Biochemistry, 13(1), 39-47.

Yapo, B.M. (2009). Pectin quantity, composition and physicochemical behaviour as influenced by the purification process. Food Research International, 42(8), 1197-1202. https://doi.org/10.1016/ j.foodres.2009.06.002

Zhang, Q., Ames, J. M., Smith, R.D., Baynes, J.W. and Metz, T.O. (2008). A perspective on the Maillard reaction and the analysis of protein glycation by mass spectrometry: probing the pathogenesis of chronic disease. Journal of Proteome Research, 8(2), 754-769. https://doi.org/10.1021/pr800858h 